\title{
Conditional human VEGF-mediated vascularization in chicken embryos using a novel temperature- inducible gene regulation (TIGR) system
}

\author{
Wilfried Weber, René R. Marty, Nils Link, Martin Ehrbar ${ }^{1}$, Bettina Keller, \\ Cornelia C. Weber ${ }^{1}$, Andreas H. Zisch ${ }^{1}$, Christoph Heinzen ${ }^{2}$, Valentin Djonov ${ }^{3}$ and \\ Martin Fussenegger*
}

Institute of Biotechnology, Swiss Federal Institute of Technology Zurich, ETH Hoenggerberg, CH-8093 Zurich, Switzerland, ${ }^{1}$ Department of Materials and Institute for Biomedical Research, ETH Zurich and University of Zurich, $\mathrm{CH}-8044$ Zurich, Switzerland, ${ }^{2}$ Inotech Encapsulation AG, Kirchstrasse 1, CH-5605 Dottikon, Switzerland and ${ }^{3}$ Institute of Anatomy, University of Bern, CH-3009 Bern, Switzerland

Received February 26, 2003; Revised and Accepted April 28, 2003

\begin{abstract}
Advanced heterologous transcription control systems for adjusting desired transgene expression are essential for gene function assignments, drug discovery, manufacturing of difficult to produce protein pharmaceuticals and precise dosing of gene-based therapeutic interventions. Conversion of the Streptomyces albus heat shock response regulator (RheA) into an artificial eukaryotic transcription factor resulted in a vertebrate thermosensor (CTA; cold-inducible transactivator), which is able to adjust transcription initiation from chimeric target promoters $\left(\mathrm{P}_{\text {СTA }}\right)$ in a low-temperatureinducible manner. Evaluation of the temperaturedependent CTA-P ${ }_{\text {СTA }}$ interaction using a tailored ELISA-like cell-free assay correlated increased affinity of CTA for $P_{\text {CTA }}$ with temperature downshift. The temperature-inducible gene regulation (TIGR) system enabled tight repression in the chicken bursal B-cell line DT40 at $41^{\circ} \mathrm{C}$ as well as precise titration of model product proteins up to maximum expression at or below $37^{\circ} \mathrm{C}$. Implantation of microencapsulated DT40 cells engineered for TIGR-controlled expression of the human vascular endothelial growth factor $A\left(\right.$ hVEGF $\left._{121}\right)$ provided low-temperature-induced VEGF-mediated vascularization in chicken embryos.
\end{abstract}

\section{INTRODUCTION}

Molecular responses to environmental temperature changes have evolved throughout living systems. Major response phenotypes include cold tolerance (1-3) and heat shock phenomena $(1,4-7)$. In prokaryotes, adaptation to elevated temperatures may result from short-term climatic changes or habitat switches, which are typical for human pathogenic bacteria. The molecular basis for temperature sensing includes (i) chaperone-mediated detection of denatured or misfolded proteins (8); (ii) temperature-dependent allosteric changes in thermosensors $(7,9)$; (iii) promoter-adjusting DNA supercoiling (10); or (iv) translation-modulating temperatureresponsive mRNA secondary structures $(5,11)$.

In Streptomyces albus, thermotolerance is mediated by the heat shock protein 18 (HSP18) whose expression is controlled by a divergently encoded thermosensor RheA (12). At low temperature, $\leqslant 30^{\circ} \mathrm{C}$, RheA binds to a dyad symmetrical operator ( $r h e O$ ) overlapping the -35 and -10 boxes of the divergently oriented rhe A and hspl 18 promoters $\left(\mathrm{P}_{\text {rheA }}\right.$ and $\mathrm{P}_{\text {hsp 18) }}$ ) and represses both genes (13). Within $<1$ min following a temperature upshift to $41^{\circ} \mathrm{C}$, allostery-based disruption of the RheA-rheO interaction results in concomitant derepression of $\mathrm{P}_{r h e A}$ and $\mathrm{P}_{h s p 18}$ and induction of HSP18-mediated thermotolerance. Autoregulated RheA expression at elevated temperatures provides high repressor levels, which are required for immediate reversion of the HSP18 production mode following a shift back to standard growth temperatures $\left(30^{\circ} \mathrm{C}\right)(7)$.

In order to evaluate whether molecular thermometers are functional in a eukaryotic cell context, we have converted the Streptomyces RheA-rheO interaction into a temperatureinducible gene regulation (TIGR) system. TIGR-controlled expression of human vascular endothelial growth factor $\mathrm{A}$ $\left(\mathrm{hVEGF}_{121}\right)$ in chicken bursal B cells (DT40) was silent at $41^{\circ} \mathrm{C}$ and could be cold induced to maximum expression levels at $37^{\circ} \mathrm{C}$. Cold-induced angiogenesis was confirmed in chicken embryos following implantation of microencapsulated DT40 cell derivatives encoding a TIGR-based temperature-responsive $\mathrm{hVEGF}_{121}$ expression unit.

\section{MATERIALS AND METHODS}

Plasmid construction

The cold-inducible transactivator CTA (RheA-VP16) was constructed by cloning the S.albus G (strain J1074) rheA gene,

*To whom correspondence should be addressed. Tel: +41 1 633 3448; Fax: +41 1633 1051; Email: fussenegger@ biotech.biol.ethz.ch 
amplified from pOLP12B [kindly provided by P. Mazodier (7)] by PCR using oligonucleotides OWW127: 5'-gtacgaattcccaccatgaccaccgecgaccgccc- $3^{\prime}$ and OWW128: $5^{\prime}$-gcgegcggctgtacgcggaggaccgcceggacgaggcc- $3^{\prime}$, digested by EcoRIBssHII into the corresponding sites of pWW35 (14) (pWW251). pWW255 was constructed by cloning of $P_{h E F 1 \alpha}$ [excised from pWW29 (14)] digested by SspI-EcoRI into pWW251. The cold-inducible CTA-dependent promoter $\mathrm{P}_{\mathrm{CTA}}$ was assembled by amplifying $\mathrm{P}_{\mathrm{hCMVmin}}$ from pWW37 (14) using oligonucleotides OWW129: 5'-gatcgacgtctgtcatcgttcggatgacacctgcaggtcgagctcggtacccggg $t c-3^{\prime}$ [RheAspecific operator site (rheO) underlined] and OWW22 (14) and cloning it digested by AatII-EcoRI into pWW37 (pWW253). For construction of pWW254, the Bacillus stearothermophilus-derived secreted $\alpha$-amylase (SAMY)encoding SpeI-HindIII fragment from pSS193 (15) was ligated (XbaI-HindIII) into pWW253. The autoregulated SAMY expression vector pWW259 was constructed by cloning CTA excised (SpeI-XbaI) from pWW255 into the NheI site of pWW254. hVEGF $_{121}$ was amplified by RT-PCR from a human aortic smooth muscle cell mix using oligonucleotides OCW76: $5^{\prime}$-cgcggtaccatgaactttctgctgtcttggg- $3^{\prime}$ and OCW77: $5^{\prime}$-cgeggatcetcaccgcctcggettgtc- $3^{\prime}$ and cloned (KpnI-BamHI) into pcDNA3 (Invitrogen, Carlsbad, CA) (pcDNA-hVEGF 121 ). hVEGF $_{121}$ was reamplified using OWW134: 5'-ggtctagaccaccatgaactttctgctg- $3^{\prime}$ and OWW135: $5^{\prime}$-ctcgagtcaccgcctcgg- $3^{\prime}$ and ligated into pEF6/V5-His TOPO (Invitrogen) (pWW276). pWW277 was constructed by excising $\mathrm{hVEGF}_{121}$ from pWW276 using XbaI-XhoI and cloning it into pWW253. The prokaryotic CTA expression vector pWW317 was constructed by amplification of CTA from pWW255 using OWW312: 5'-cggaattcccaccatgcatatgaccaccgccgaccgc- $3^{\prime}$ and OWW313: $5^{\prime}$-gctctagagcaagcttctacccaccgtactcgtcaattc- $3^{\prime}$ and ligation (NdeI-HindIII) into pRSETmod [modified pRSET vector (16)]. A 227 bp biotinylated rheO-encoding DNA fragment was assembled by amplification of rheO using oligonucleotides OWW64: biotin-5'ggggttccgcgcacatttccec- $3^{\prime}$ and OWW22 (14) and pWW254 as template. All PCR products were confirmed by DNA sequencing.

\section{Cell culture and reporter gene assays}

The chicken bursal lymphoma cell line DT40 (ATCC CRL-2111) was cultivated as described (17).

SAMY was quantified as units per liter (U/l) as described before (15), and hVEGF $_{121}$ was assessed using a human VEGF DuoSet enzyme-linked immunosorbent assay (ELISA; R\&D Systems, Minneapolis, MO; cat. no. DY293) according to the manufacturer's protocol.

\section{Electroporation of DT40 cells}

For electroporation-based transfection, 5-8 $\times 10^{5}$ exponentially growing DT40 cells $/ \mathrm{ml}$ were centrifuged at $450 \mathrm{~g}$ for $3 \mathrm{~min}$, and $4 \times 10^{6}$ cells were resuspended in $0.4 \mathrm{ml}$ of serumfree RPMI-1640 medium. The cells were mixed with $30 \mu \mathrm{g}$ of DNA per plasmid and transferred to a Gene Pulser Cuvette (Bio-Rad Laboratory AG, Glattbrugg, Switzerland; cat. no. 165-2088). Electroporation was performed using a Bio-Rad Gene Pulser II and the following settings, resulting in typical time constants of $45 \mu \mathrm{s}$ : capacitance, $960 \mu \mathrm{F}$; voltage, $360 \mathrm{~V}$; resistance, $\mathrm{R}=\infty$. Electroporation of
DT40 resulted in a typical transfection efficiency of $42 \pm 5 \%$. After electroporation, the transfected cells were diluted in $12 \mathrm{ml}$ of complete RPMI-1640 medium and cultivated as described.

\section{Western blot analysis of CTA}

A $1 \mathrm{ml}$ culture from an Escherichia coli CTA production strain was subjected to western blotting following detection using a mouse anti-VP16 antibody (Santa Cruz Biotechnology Inc., Santa Cruz, CA; cat. no. sc-7545) and an anti-mouse horseradish peroxidase (HRP)-coupled secondary antibody as described below.

\section{ELISA-based cell-free analysis of CTA-P ${ }_{\text {CTA }}$ interactions}

For production of CTA, pWW317 ( $\left.\mathrm{P}_{\mathrm{T} 7}-\mathrm{CTA}-\mathrm{pA}\right)$ was transformed into E.coli BL21* (DE3)pLysS (Invitrogen; cat. no. C6010-03) and transgenic E.coli strains were grown to an $\mathrm{OD}_{600}$ of 1.2 prior to isopropyl- $\beta$-D-thiogalactopyranoside$(1 \mathrm{mM})$ mediated induction for 3-4 h. Lysates were produced by lysozyme treatment $(0.2 \mathrm{mg} / \mathrm{ml})$ for $45 \mathrm{~min}$ at $37^{\circ} \mathrm{C}$ and the DNA was fragmented by sonication (five bursts of $2 \mathrm{~s}$ at $75 \mathrm{~W}$ using a Branson Sonifier 450; Branson Ultrasonic Corp., Carouge, Switzerland). The supernatant was clarified by centrifugation at $21000 \mathrm{~g}$ for $30 \mathrm{~min}$ and $4^{\circ} \mathrm{C}$. ELISA plates (Corning, New York, NY; cat. no. 3590) were coated overnight with $100 \mu \mathrm{l} /$ well streptavidin solution $(6 \mu \mathrm{g} / \mathrm{ml})$ at $37^{\circ} \mathrm{C}$ while shaking at 250 r.p.m., and blocked for $2 \mathrm{~h}$ using blocking solution [1\% blocking reagent (Roche Molecular Biochemicals, Rotkreuz, Switzerland; cat. no. 1-096-176) in TBS (20 mM Tris-HCl, $150 \mathrm{mM} \mathrm{NaCl}, \mathrm{pH}$ 7.6) and $10 \mathrm{mM}$ EDTA]. The blocking solution was removed and the plates were washed four times with TBS-Tween (TBST). A $100 \mu \mathrm{l}$ aliquot of a $2 \mu \mathrm{g} / \mathrm{ml}$ solution containing biotinylated rheOencoding DNA in blocking solution was added per well and incubated for $1 \mathrm{~h}$. As in all subsequent incubation steps, the sample was kept at $23^{\circ} \mathrm{C}$ and was shaken at 250 r.p.m. After washing each well four times with $400 \mu \mathrm{l}$ of pre-warmed TBST, $30 \mu \mathrm{l}$ of CTA-containing crude cell extract (containing $0.5 \mu \mathrm{g}$ of CTA in $100 \mu \mathrm{l}$ of protein in blocking solution) was added per well, followed by incubation for $1 \mathrm{~h}$. The wells were washed four times with $400 \mu \mathrm{l}$ of TBST, filled with $100 \mu \mathrm{l}$ of blocking solution per well and incubated at different temperatures for $1 \mathrm{~h}$. After washing four times with $400 \mu \mathrm{l}$ of TBST pre-warmed at appropriate temperatures, the wells were incubated with a 1:200 dilution of monoclonal mouse antiVP16 antibody (Santa Cruz Biotechnology; cat. no. sc-7545) in blocking solution for $1 \mathrm{~h}$. The primary antibody was removed, and the wells were washed four times with $400 \mu \mathrm{l}$ of TBST and incubated for $30 \mathrm{~min}$ with the secondary HRPcoupled anti-mouse IgG (Amersham Pharmacia Biotech, Dubendorf, Switzerland; cat. no. NA931, lot. no. 168416) diluted 1:200 in blocking solution without EDTA. The chromogenic reaction was initiated by addition of $100 \mu \mathrm{l}$ of 3,3',5,5'-tetramethylbenzidine (TMB) substrate solution (Sigma Chemicals, St Louis, MO; cat no. T-8665), stopped by addition of $25 \mu \mathrm{l}$ of $1 \mathrm{M} \mathrm{H}_{2} \mathrm{SO}_{4}$, and quantified by absorbance readings taken at $450 \mathrm{~nm}$ on a SpectraMax Plus (Molecular Devices, Sunnyvale, CA). 


\section{Microencapsulation of DT40 cells}

At $20 \mathrm{~h}$ post-electroporation, DT40 cells were microencapsulated in alginate-poly-L-lysine-alginate beads using the Inotech Encapsulator Research IER-20 as previously described (14). Microencapsulated DT40 cells were cultivated in $10 \mathrm{ml}$ of complete RPMI-1640 medium for $24 \mathrm{~h}$ at $41^{\circ} \mathrm{C}$ prior to implantation into the chicken embryo $(14,16)$.

\section{Monitoring vascularization in chicken embryos}

Experiments involving chicken embryos were conducted following the shell-free cultivation protocols of Djonov et al. (18). After 3 days of incubation at $37^{\circ} \mathrm{C}$, Brown Leghorn eggs were opened and their contents carefully poured into plastic Petri dishes of $80 \mathrm{~mm}$ in diameter. The chicken embryos were incubated further for 6 days at $37^{\circ} \mathrm{C}$ in a humidified atmosphere. On embryonic day 9, $50 \mu \mathrm{l}$ of a concentrated capsule solution (750 microcapsules containing 200 DT40 cells/capsule) containing microencapsulated DT40 cells engineered for TIGR-controlled $\mathrm{hVEGF}_{121}$ production was injected under the chorioallantoic membrane (CAM) or placed onto the CAM. The embryos were cultivated for a further 2 days at 37 and $41^{\circ} \mathrm{C}$, respectively. At embryonic day 11, the CAMs were examined by in vivo fluorescence microscopy. Micrographs were taken following intravenous injections of $100 \mu \mathrm{l}$ of $2.5 \%$ fluorescein isothiocyanate (FITC)-dextran 2000000 (Sigma Chemicals) (19). The developing blood vessels were monitored using a PolyvarReichert fluorescence microscope (Leica AG, Heerbrugg, Switzerland) at 25-fold magnification. The microscope was equipped with a custom-built heating table to maintain the temperature of the specimens at the desired temperatures (37 or $41^{\circ} \mathrm{C}$ ). Blood circulation and microvascular patterns were monitored for $15 \mathrm{~min}$ for every CAM using a LE CCD Optronics video camera (Visitron system, Puchheim, Germany) and a digital video recorder (Sony, DHR-1000 VC, Sony AG, Schlieren, Switzerland).

\section{Morphological analysis of vascularization}

CAM samples were fixed at embryonic day 11 in $2.5 \%$ glutaraldehyde [buffered with $30 \mathrm{mM}$ potassium phosphate (370 mOsm; pH 7.4)], stained in 1\% osmium tetroxide [buffered with 0.1 M sodium cacodylate (340 mOsm; $\mathrm{pH} 7.4$ )], dehydrated in ethanol, and embedded in Epon 812 as described before (20). Sections $1 \mu \mathrm{m}$ thick were prepared using glass knives, stained with toluidine blue, and examined on an Leitz DM-RBE light microscope (Leica AG, Heerbrugg, Switzerland) equipped with a JVC KY-F70 video camera (Spietzer Electronic AG, Oberwil, Switzerland). Furthermore, 80-90 nm thick sections were generated, transferred onto Formvar-coated (polyvinyl formal; Fluka Chemie AG, Buchs, Switzerland) copper grids, double-stained with lead citrate and uranyl acetate, and monitored using a Philips EM 400 transmission electron microscope (18).

\section{Methylmethacrylate $\left(\operatorname{Mercox}^{\circledR}\right)$ casting}

Mercox $^{\circledR}$ (Japan Vilene Company) casts of CAM vessels were prepared at embryonic day 11. The vasculature was perfused with a $0.9 \%$ sodium chloride solution containing $1 \%$ Liqemin $^{\circledR}$ and Procaine ${ }^{\circledR}$, followed by a freshly prepared Mercox ${ }^{\circledR}$ solution containing $0.1 \mathrm{ml}$ of accelerator per $5 \mathrm{ml}$ of resin. At $2 \mathrm{~h}$ after perfusion, the CAMs were excised and immersed in Ringer's solution for $\sim 2 \mathrm{~h}$ and subsequently transferred to $15 \% \mathrm{KOH}$ for 2-4 weeks for dissolution of the tissue. After washing, the casts were dehydrated in a graded series of increasing ethanol concentrations and dried in a vacuum desiccator (18). Samples were mounted on aluminum stubs with carbon and sputtered with gold. They were examined in a Philips XL 30 FEG scanning electron microscope.

\section{RESULTS}

\section{Design of the low temperature-inducible gene regulation system}

Previous design concepts of heterologous transgene control systems for vertebrates/vertebrate cells included a regulating small molecule that modulates the affinity of an artificial transactivator for its specific target promoter and thus adjusts desired transgene expression in response to a moleculespecific dosing regime $(21,22)$. Unfortunately, many regulating agents proved to be toxic, elicited short- and long-term side effects or have not yet been clinically licensed (21-25). In order to avoid deficiencies often found to be associated with regulating small molecules, gene control systems that could be fine-tuned by physical parameters such as temperature would represent a valuable alternative to current technologies.

The generic cold-inducible transcription control system consists of two chimeric genetic determinants, CTA and its cognate promoter $\left(\mathrm{P}_{\mathrm{CTA}}\right)$. CTA was constructed by fusing the S.albus heat shock response regulator RheA $3^{\prime}$ to the herpes simplex VP16 transactivation domain [CTA, RheA-VP16 $(7,26)] . P_{\text {CTA }}$ was assembled by cloning a RheA-specific operator module (rheO, TGTCATCGTTCGGATGACA) 5' to a minimal version of the human cytomegalovirus immediate early promoter $\left[\mathrm{P}_{\mathrm{hCMVmin}} ; \mathrm{P}_{\mathrm{CTA}}\right.$, rheO $-\mathrm{P}_{\mathrm{hCMVmin}}$ $(14,27)$ ] (Fig. 1). Western blot analysis of CTA produced in E.coli revealed a protein of $38 \mathrm{kDa}$ correlating with the deduced molecular weight of a full-length RheA-VP16 fusion protein $(36.8 \mathrm{kDa})$ ( $\mathrm{pWW} 317, \mathrm{P}_{\mathrm{T} 7}-\mathrm{CTA}-\mathrm{pA}$; data not shown).

\section{Thermosensitivity assessment of the CTA-P ${ }_{\text {CTA }}$ interaction using a cell-free assay}

Investigation of whether CTA retains its RheA-typical thermo-adjustable affinity for rheO required the design of an ELISA-based set-up tailored to quantify the CTA-P ${ }_{\mathrm{CTA}}$ interaction in a cell-free assay. A biotin-labeled $\mathrm{P}_{\mathrm{CTA}^{-}}$ encoding PCR fragment immobilized on a streptavidin-coated multi-well plate was incubated with the lysate of an E.coli CTA production strain at varying temperatures prior to VP16targeted quantification of CTA- $\mathrm{P}_{\mathrm{CTA}}$ interaction using a standard colorimetric assay (Fig. 2). When configured in this way, the ELISA demonstrated that decreasing binding affinity of CTA for $\mathrm{P}_{\mathrm{CTA}}$ correlated with increasing temperatures $\left(23,25,28,31\right.$ and $37^{\circ} \mathrm{C}$, Fig. 2). Thus, CTA has the potential to function as a molecular thermometer that translates temperature changes into site-specific DNA-binding capacity. Furthermore, since CTA has been designed as a generic sequence-specific transcription activator, its binding to 


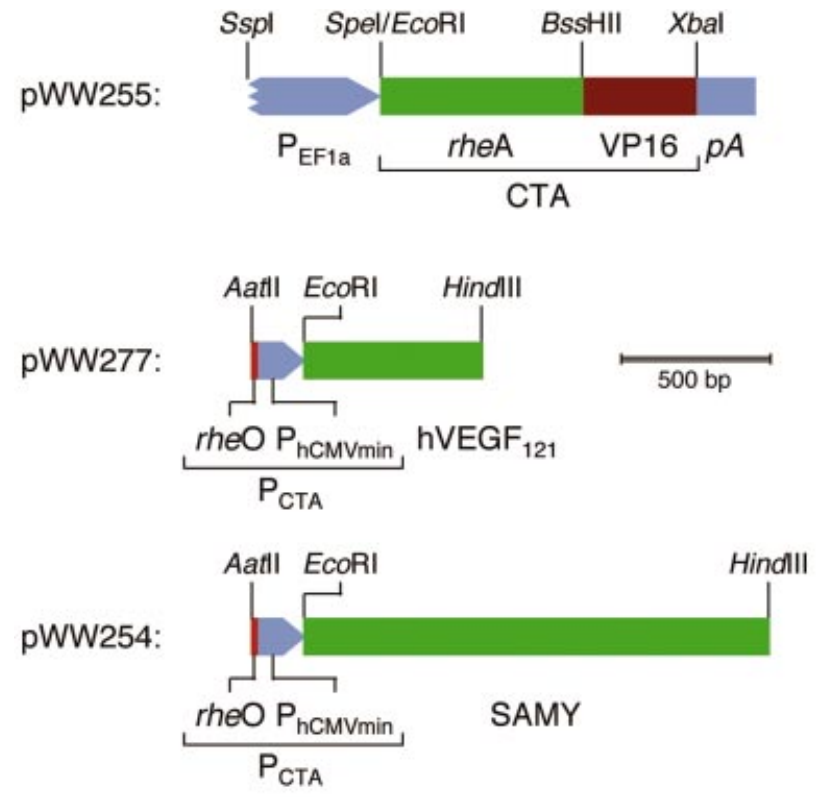

$37^{\circ} \mathrm{C}$

$41^{\circ} \mathrm{C}$

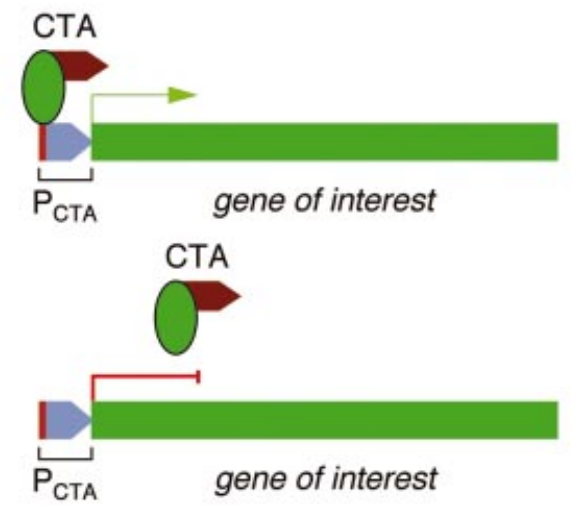

Figure 1. TIGR system. Top three expression units show the molecular details of TIGR. The cold-inducible transactivator (CTA) was constructed by fusing the S.albus heat shock response regulator rheA to the VP16 transactivation domain of herpes simplex virus (CTA, rheA-VP16). CTA was placed under control of the human elongation factor $1-\alpha$ promoter, which mediates constitutive high level expression in chicken cells (pWW255, $\mathrm{P}_{\mathrm{hEFI} \alpha-\mathrm{CTA}} \mathrm{pA}$ ). The CTA-responsive target promoter $\mathrm{P}_{\mathrm{CTA}}$ was assembled by cloning a single rheA-specific operator module ( $r h e O)$ adjacent to a minimal version of the human cytomegalovirus immediate early promoter $\left(\mathrm{P}_{\mathrm{hCMV} m i n}\right)\left(\mathrm{P}_{\mathrm{CTA}}\right.$, rheO- $\left.\mathrm{P}_{\mathrm{hCMV} \text { min }}\right) . \mathrm{P}_{\mathrm{CTA}}$ was configured to drive either the cDNA encoding the human vascular endothelial growth factor A $\left(\mathrm{hVEGF}_{121} ; \mathrm{pWW} 277, \mathrm{P}_{\mathrm{CTA}_{\mathrm{A}}}-\mathrm{hVEGF}_{121}-\mathrm{pA}\right)$ or the SAMY reporter gene (pWW254, $\left.\mathrm{P}_{\mathrm{CTA}}-\mathrm{SAMY}-\mathrm{pA}\right)$. Selected sites for restriction endonucleases are indicated. Bottom two expression units illustrate TIGR-controlled transgene expression at different temperatures. At the permissive temperature of $37^{\circ} \mathrm{C}$, CTA binds and transactivates $\mathrm{P}_{\mathrm{CTA}}$, which results in expression of the gene of interest. At $41^{\circ} \mathrm{C}$, the $\mathrm{P}_{\text {CTA }}$ binding affinity of CTA is abolished and expression of the gene of interest remains silent.

$\mathrm{P}_{\mathrm{CTA}}$ at low temperatures is expected to initiate transcription of $\mathrm{P}_{\mathrm{CTA}}$-driven transgenes in the absence of any exogenous molecule.

\section{Temperature-dependent fine-tuning of TIGR-driven transgene expression in vertebrate cells}

Since chicken cells show an unmatched range of cultivation temperatures, we chose the chicken bursal lymphoma cell line
A
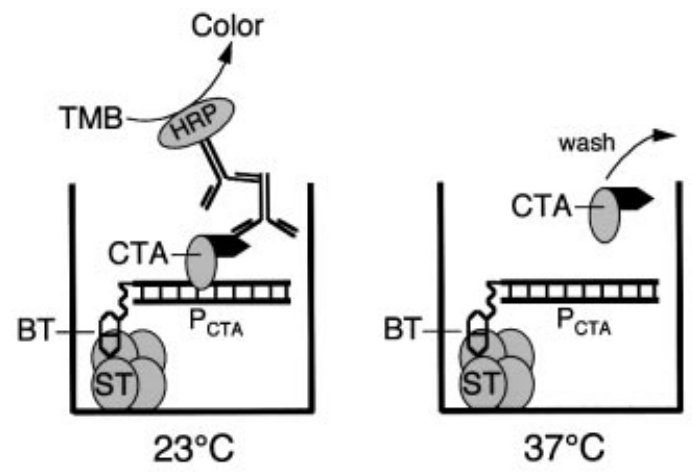

B

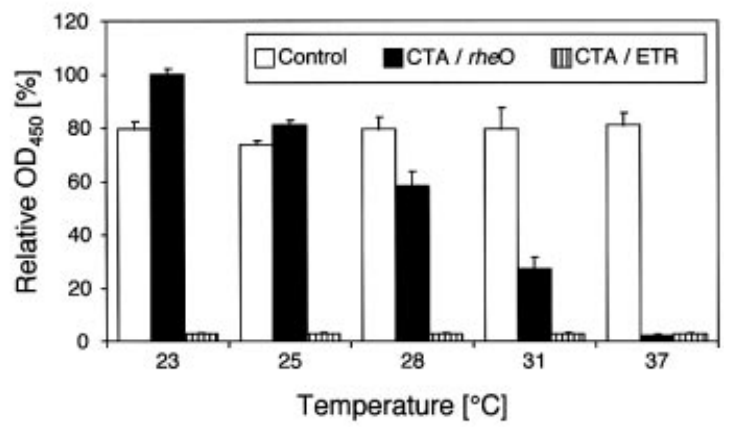

Figure 2. ELISA-based quantification of the thermosensitivity of the CTA- $\mathrm{P}_{\text {СTA }}$ interaction. (A) Schematic representation for scoring the CTA affinity for $\mathrm{P}_{\text {CTA }}$. A PCR-generated biotin (BT)-labeled $\mathrm{P}_{\mathrm{CTA}}$ fragment is immobilized via streptavidin (ST) in a multi-well chamber. This set-up is incubated with the lysate of an E.coli CTA production strain (harboring pWW317, $\mathrm{P}_{\mathrm{T} 7}$-CTA-pA) at different temperatures. After washing steps, the affinity of CTA for $\mathrm{P}_{\mathrm{CTA}}$ is quantified by anti-VP16-based immunodetection visualized by an HRP-conjugated secondary antibody (targeted against the Fc region of the anti-VP16 antibody) which converts TMB into a color readout at $450 \mathrm{~nm}$. (B) Quantitative ELISA-based cell-free analysis of CTA-P $\mathrm{P}_{\text {СTA }}$ interaction at different temperatures. Whereas CTA showed lower affinity for its cognate $r h e O$ operator module at increasing temperatures (black bars), the interaction of the control configuration consisting of the macrolide-responsive transactivator (ET1) and its target sequence ETR was insensitive to temperature changes (white bars). Furthermore, the CTA binding capacity was specific for $r h e O$ as it did not interact with the ETR operator module at any of the temperatures (shaded bars).

DT40 for validation of the TIGR technology in vertebrate cells $(17,28)$. When cloned into a vertebrate expression configuration (pWW255, $\mathrm{P}_{\mathrm{hEF} 1 \alpha^{-}} \mathrm{CTA}-\mathrm{pA}$ ) and transfected into DT40 cells, CTA production did not change the growth profile of the chicken cell line, indicating that this chimeric transactivator has no significant impact on host cell physiology (doubling times of 15.3 and $15.8 \mathrm{~h}$ for wild-type and CTA-expressing DT40 cells cultivated at $41^{\circ} \mathrm{C}$ ). When co-transfected with a reporter plasmid encoding $\mathrm{P}_{\mathrm{CTA}}$-driven SAMY [pWW254;

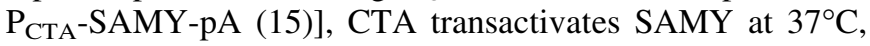
while expression of this reporter gene remains silent at $41^{\circ} \mathrm{C}$ (Fig. 3). CTA-mediated transactivation of $\mathrm{P}_{\mathrm{CTA}}$ results in expression levels comparable with wild-type $P_{h E F 1 \alpha}$, which itself remains insensitive to temperature changes (Fig. 3). In principle, TIGR-controlled gene expression also works in mammalian cells, as exemplified by $\mathrm{CHO}$ cells transfected by TIGR-controlled SAMY expression $\left(34^{\circ} \mathrm{C}, 90 \pm 11 \mathrm{U} / 1 ; 41^{\circ} \mathrm{C}\right.$, $34 \pm 8.7 \mathrm{U} / 1)$. 


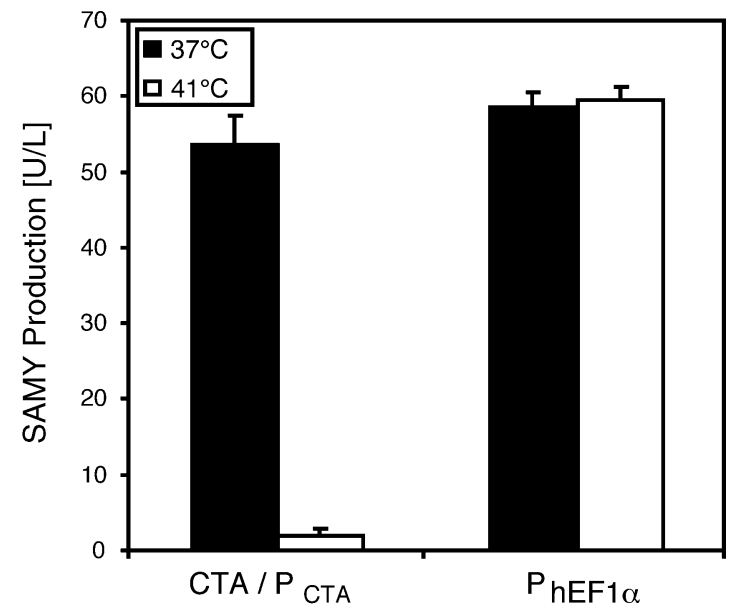

Figure 3. TIGR-mediated temperature-dependent transgene expression switches in chicken DT40 cells. Triplicate DT40 cultures were co-transfected with the CTA expression construct pWW255 ( $\left.\mathrm{P}_{\mathrm{hEF} 1 \alpha}-\mathrm{CTA}-\mathrm{pA}\right)$ as well as the CTA-responsive SAMY expression vector pWW254 ( $\mathrm{P}_{\mathrm{CTA}^{-}}$ SAMY-pA) and incubated at 37 and $41^{\circ} \mathrm{C}$. At $48 \mathrm{~h}$ post-transfection, SAMY expression profiles were quantified in the supernatant of both cultures. DT40 control cells transfected with the constitutive SAMY expres-

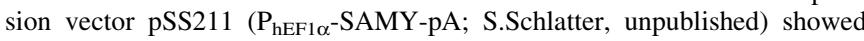
similar reporter gene expression profiles at both temperatures.

Beyond simple switch on and off characteristics, TIGRcontrolled SAMY expression was adjustable and could be fine-tuned to any desired level following incubation of engineered DT40 cell lines at intermediate temperatures (doubling times: $37^{\circ} \mathrm{C}, 20.8 \mathrm{~h} ; 38^{\circ} \mathrm{C}, 15.8 \mathrm{~h} ; 39^{\circ} \mathrm{C}, 15.6 \mathrm{~h}$; $\left.40^{\circ} \mathrm{C}, 15.4 \mathrm{~h} ; 41^{\circ} \mathrm{C}, 15.3 \mathrm{~h}\right)$. In this configuration, the molecular thermometer CTA could reliably translate temperature changes of a degree with unmatched precision into desired transgene expression levels (Fig. 4). Interestingly, the temperature range effective for modulating the $\mathrm{CTA}-\mathrm{P}_{\mathrm{CTA}}$ interaction varies significantly between cell-free $\left(37-23^{\circ} \mathrm{C}\right)$ and cell-based systems $\left(41-37^{\circ} \mathrm{C}\right)$. Thus, RheA fusions partners and/or cell-specific protein cocktails interacting with fused domains are expected to modify RheA's responsiveness to temperature, which will enable precise adaptation of the TIGR system to a desired cellular context or temperature range.

The TIGR configuration based on two plasmids encoding constitutive CTA and $\mathrm{P}_{\mathrm{CTA}}$-driven transgene expression units was further refined by designing a one-vector-based autoregulated cold-inducible expression unit. This autoregulated set-up consisted of a $\mathrm{P}_{\mathrm{CTA}}$-controlled dicistronic expression cassette encoding SAMY in the first and CTA in the second cistron [pWW259, $\mathrm{P}_{\mathrm{CTA}^{-}}$-SAMY-IRES-CTA-pA; IRES, internal ribosome entry site of polioviral origin (29)]. Leaky $\mathrm{P}_{\mathrm{CTA}}$-driven dicistronic transcript results in few CTAs that initiate a positive feedback loop, resulting in high level expression of the transactivator as well as the co-cistronically encoded reporter gene SAMY at permissive temperatures. Besides its compact one-vector configuration, the autoregulated expression set-up compares favorably with the binary TIGR design (autoregulated: $41^{\circ} \mathrm{C}, 5.8 \pm 0.2 \mathrm{U} / \mathrm{l} ; 37^{\circ} \mathrm{C}$, $65.1 \pm 4.3 \mathrm{U} / 1 ;$ binary: $41^{\circ} \mathrm{C}, 4.4 \pm 0.1 \mathrm{U} / 1 ; 37^{\circ} \mathrm{C}$, $56.5 \pm 3.6 \mathrm{U} / \mathrm{l})$.

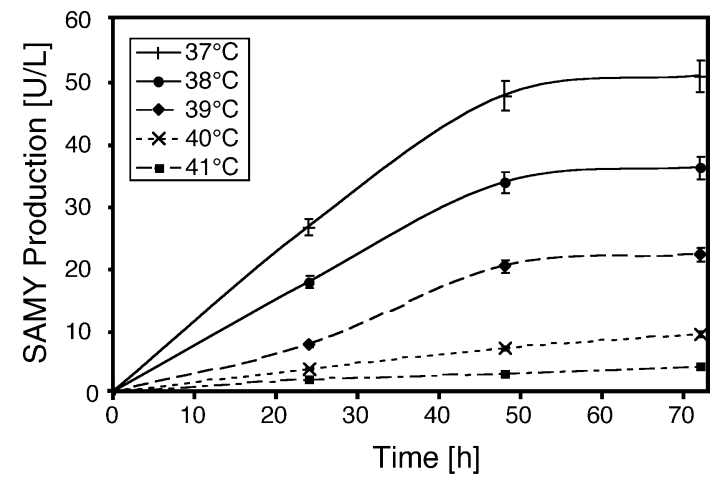

Figure 4. Temperature adjustability of the TIGR system. DT40 cells cotransfected with pWW255 ( $\mathrm{P}_{\mathrm{hEF} 1 \alpha}$-CTA-pA) and pWW254 ( $\mathrm{P}_{\mathrm{CTA}}$-SAMY$\mathrm{pA})$ were incubated at varying temperatures, and SAMY production profiles were quantified at different time points post-transfection.

TIGR-controlled production of human VEGF following implantation of microencapsulated and transfected DT40 cells into chicken embryos

For validation of the low-temperature-induced gene expression system in vivo, we chose to transplant DT40 cells transfected for TIGR-controlled $\mathrm{hVEGF}_{121}$ into chicken embryos (pWW255, $\mathrm{P}_{\mathrm{hEF} 1 \alpha}-\mathrm{CTA}-\mathrm{pA} ; \mathrm{pWW} 277, \mathrm{P}_{\mathrm{CTA}^{-}}$ $\left.\mathrm{hVEGF}_{121}-\mathrm{pA}\right)$. Since direct sub-CAM implantation of DT40 cells was lethal for the chicken embryos in initial experiments, we encapsulated the DT40 cell derivatives in alginate-poly-L-lysine-alginate beads. Microencapsulated TIGR-responsive hVEGF $_{121}$ production cell lines showed identical temperature induction profiles and maximum expression levels of this growth factor, indicating that encapsulation does not impair the overall regulation performance of the TIGR system (non-encapsulated DT40: $41^{\circ} \mathrm{C}, 25.9 \pm$ $3.5 \mathrm{ng} / \mathrm{ml} ; 37^{\circ} \mathrm{C}, 168 \pm 19 \mathrm{ng} / \mathrm{ml}$; encapsulated DT40: $\left.41^{\circ} \mathrm{C}, 21.9 \pm 0.6 \mathrm{ng} / \mathrm{ml} ; 37^{\circ} \mathrm{C}, 171 \pm 19 \mathrm{ng} / \mathrm{ml}\right) . \mathrm{hVEGF}_{121}$ produced in chicken cells is glycosylated in a different manner compared with mammalian cells (data not shown).

Microencapsulated DT40 cells engineered for TIGRcontrolled $\mathrm{hVEGF}_{121}$ expression were implanted into chicken embryos and placed onto the CAM. The chicken embryos were grown at 37 and $41^{\circ} \mathrm{C}$ for 2 days prior to microscopical analysis of the vascularization of the CAM. hVEGF $_{121^{-}}$ mediated vascularization could only be monitored in chicken embryos incubated at $37^{\circ} \mathrm{C}$, whereas control embryos containing capsules only or capsules with non-engineered DT40 cells displayed a regular wild-type pattern of blood vessels, which was insensitive to temperature changes (Fig. 5). Constitutive hVEGF $_{121}$ expression in DT40 cells transplanted into chicken embryos cultivated at $41{ }^{\circ} \mathrm{C}$ showed vascularization patterns comparable with TIGR-controlled growth factor production at $37^{\circ} \mathrm{C}$, indicating that $\mathrm{hVEGF}_{121}$ remains active at elevated temperatures (data not shown).

\section{DISCUSSION}

Gene-function correlations are one of the major challenges in the post-genomic era. Owing to their unmatched gene targeting frequencies, stability and easy handling, the chicken bursal B-cell line DT40 has become a cornerstone in recent 

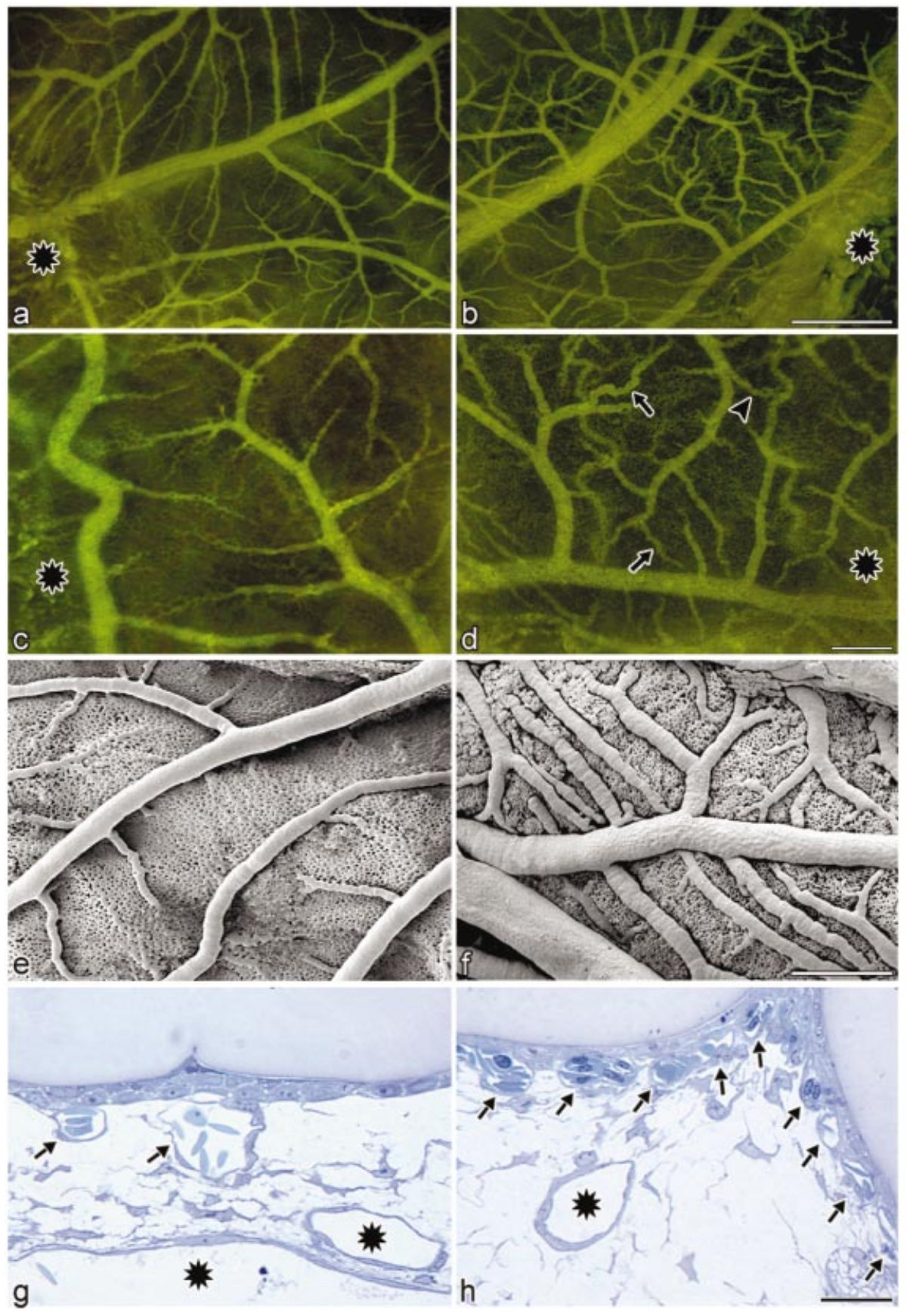

Figure 5. $\mathrm{hVEGF}_{121}$-mediated vascularization in chicken embryos. Parallel grafting experiments were performed following supra-CAM application of microencapsulated DT40 cells engineered for TIGR-controlled $\mathrm{hVEGF}_{121}$ and incubation at $41^{\circ} \mathrm{C}\left(\mathrm{a}, \mathrm{c}, \mathrm{e}\right.$ and $\mathrm{g}$ ) and $37^{\circ} \mathrm{C}(\mathrm{b}, \mathrm{d}, \mathrm{f}$ and $\mathrm{h}$ ) for 2 days (until embryonic day 11). (a-d) Still video images of the growing CAM microvasculature at embryonic day 11 (application site indicated by asterisks) following intravenous injection of FITC-dextran ( $a$ and b overview; $c$ and d insets of a and b at higher magnification). As shown in (b) and (d) in comparison with (a) and (c), only TIGR-mediated induction of $\mathrm{hVEGF}_{121}$ at $37^{\circ} \mathrm{C}$ results in a massive angiogenic response exemplified by (i) the increased number of the feeding vessels; and (ii) their tortuous shape (arrows shown in d) and the formation of arterial venous shunts (arrowhead in d). Scanning electron micrographs confirm increased numbers of arterioles and veins as well as a densely packed capillary plexus in CAMs incubated at $37^{\circ} \mathrm{C}$ (f) when compared with an isogenic set-up grown at $41^{\circ} \mathrm{C}(\mathbf{e})$. Cross-sections through microcapsules and underlying CAM reveal a local angiogenic response at sites of application at $37^{\circ} \mathrm{C}(\mathbf{h})$ but not at $41^{\circ} \mathrm{C}$ (g). The wild-type CAM consisting of capillary plexus (arrows in $\mathrm{g}$ ) in the subepithelial region is transformed by TIGR-controlled production of $\mathrm{hVEGF}_{121}$ at permissive temperatures into a compact and stacked multitude of newly formed capillary vessels (arrows in $h$ ). The supplying vessels are indicated by asterisks. Size bars: (a) and (b) $=50 \mu \mathrm{m}$; (c), (d), (e) and (f) $=200 \mu \mathrm{m}$, (g) and (h) $=20 \mu \mathrm{m}$.

reverse genetics initiatives $(28,30)$. For example, DT40 cells have been essential for the elucidation of immunoglobulin somatic hypermutation and affinity maturation of antibodies, gene conversion, homologous recombination, RNA editing and the design of artificial chromosomes (17,31-35). Also, recent advances in the production of protein pharmaceuticals in the egg white of transgenic chickens and the use of chicken embryos for validation of tissue engineering and therapeutic 
angiogenesis concepts puts the DT40 chicken model system into the limelight of basic and applied research (36-38).

Rational reprogramming of vertebrate cells by conditional molecular interventions has generated dramatic impact on gene-function analysis $(39,40)$, prototype gene therapy scenarios $(14,41,42)$, tissue engineering $(43)$, design of animal models with human disease phenotypes $(40,44,45)$, drug discovery (46) and biopharmaceutical manufacturing (47-49). A variety of heterologous small molecule-responsive gene regulation systems have been designed, improved and validated in different cell culture and in vivo settings $(21,22)$. Although most available heterologous gene control systems have shown excellent performance in modulating desired transgene expression in basic research settings, the use of many of these gene switches in biopharmaceutical manufacturing, gene therapy or tissue engineering may be limited due to a combination of low or leaky expression, side effects of regulating molecules, and incompatibilities with regulatory guidelines. Antibiotic-responsive gene regulation systems $(14,27,50,51)$ and the chemically induced dimerization technology (52), which are currently competing for clinical applications, combine most assets of ideal gene control modalities: (i) regulation by a clinically licensed, bioavailable molecule devoid of long-term side effects; (ii) low leaky expression and high induction levels; (iii) optimal doseresponse characteristics; (iv) compact, preferably one-vector design; and (v) low immunogenicity. Yet accumulation of antibiotics in bone and teeth following long-term administration $(23,25)$ and the long-awaited clinical approval of nonimmunosuppressive dimerizer drugs put these systems on hold for many therapeutic settings $(14,27,51,52)$. Furthermore, precise in vivo dosing of regulating molecules remains a challenge, as most currently available gene control systems are only adjustable within a narrow drug concentration window $(14,27,51,52)$. The combination of reliable heterologous gene control configurations with physiological nonmolecule inducers might represent a decisive advancement for the gene regulation territory.

Gene switches induced by a temperature downshift display a high degree of physiological compatibility since lowtemperature cultivation is well tolerated by vertebrate cells and typically associated with increased specific productivity (53). In principle, any protein can be mutated to become temperature sensitive. For example, specific mutations rendered the RNA-dependent RNA replicase of alphaviruses temperature sensitive. Following a temperature downshift from 37 to $29^{\circ} \mathrm{C}$, the viral replicase initiates an RNA amplification loop resulting in high level expression of desired transgenes driven by subgenomic viral promoters $(54,55)$. Concerns about safety, long-term cytopathy and accumulation of mutations in product proteins produced by a viral replicase devoid of any proof-reading capacity have so far limited the use of this technology beyond basic research.

TIGR includes the first vertebrate thermosensor, which recruits the endogenous transcription initiation machinery for temperature-adjustable transgene expression. TIGR exhibits rapid response kinetics typically associated with natural temperature switches, low basal expression near the detection limit, high maximum expression levels comparable with $\mathrm{P}_{\mathrm{hEF} 1 \alpha}$, one of the strongest vertebrate promoters, and induction ratios compatible with state-of-the-art conditional molecular interventions in vertebrate cells $(40,56)$. The TIGR performance was successfully tested in an in vivo angiogenesis model: TIGR promoted solid high level expression of human $\mathrm{hVEGF}_{121}$ in chicken embryos at $37^{\circ} \mathrm{C}$, while expression of this key angiogenic factor was completely neutralized as evidenced by wild-type-like vascularization at $41^{\circ} \mathrm{C}$.

VEGF and its various splice variants are the most prominent representatives among angiogenic growth factors that induce new blood vessels from pre-existing vasculature. VEGF plays an essential role in embryonic development, normal growth of tissues, wound healing and the female reproductive cycle $(38,57-59)$. The fact that the slightest disregulation of endogenous VEGF expression is associated with severe pathologies, upregulation with neoplasia and downregulation with ischemia, explains why production of this growth factor is tightly regulated at multiple levels $(38,57-59)$. Therefore, it is not surprising that VEGF has been a 2-fold therapeutic target, and strategies to inhibit this growth factor or its targeted administration are currently in clinical trials. Although therapeutic angiogenesis achieved promising results in chronic myocardial and retinal ischemia, uncontrolled systemic delivery has been associated with hypotension, edema, accelerated atherosclerosis and endothelial cell-derived tumors $(38,58,60)$. Milestones in adjustable therapeutic delivery of VEGF included third-generation biomaterials supporting wound healing by controlled release of recombinant hVEGF and regulation of endogenous VEGF using a dimerization-dependent artificial transactivator targeted to the VEGF promoter region (61-63).

As of now, TIGR-based transcription control represents the first non-viral thermosensor for controlled transgene expression in vertebrates. Because of the simplicity of its inducer, i.e. temperature, TIGR will probably foster advances in profitable biopharmaceutical manufacturing of difficult to produce protein therapeutics and the understanding of angiogenesis.

\section{ACKNOWLEDGEMENTS}

We thank Philippe Mazodier for plasmid pOLP12B, Stefan Schlatter for plasmids pSS193 and pSS211, and Beat P. Kramer and Laetitia Malphettes for critical comments on the manuscript. This work was supported by the Swiss National Science Foundation (grant no. 631-065946), and the Swiss Federal Office for Education and Science (BBW) within EC Framework 5.

\section{REFERENCES}

1. Iba,K. (2002) Acclimative response to temperature stress in higher plants: approaches of gene engineering for temperature tolerance. Annu. Rev. Plant Biol., 53, 225-245.

2. Fujita,J. (1999) Cold shock response in mammalian cells. J. Mol. Microbiol. Biotechnol., 1, 243-255.

3. Yamanaka,K. (1999) Cold shock response in Escherichia coli. J. Mol. Microbiol. Biotechnol., 1, 193-202.

4. Hurme,R. and Rhen,M. (1998) Temperature sensing in bacterial gene regulation-what it all boils down to. Mol. Microbiol., 30, 1-6.

5. Johansson,J., Mandin,P., Renzoni,A., Chiaruttini,C., Springer,M. and Cossart,P. (2002) An RNA thermosensor controls expression of virulence genes in Listeria monocytogenes. Cell, 110, 551-561.

6. Morimoto,R.I. (2002) Dynamic remodeling of transcription complexes by molecular chaperones. Cell, 110, 281-284. 
7. Servant,P., Grandvalet,C. and Mazodier,P. (2000) The RheA repressor is the thermosensor of the HSP18 heat shock response in Streptomyces albus. Proc. Natl Acad. Sci. USA, 97, 3538-3543.

8. Gamer,J., Multhaup,G., Tomoyasu,T., McCarty,J.S., Rudiger,S., Schonfeld,H.J., Schirra,C., Bujard,H. and Bukau,B. (1996) A cycle of binding and release of the DnaK, DnaJ and GrpE chaperones regulates activity of the Escherichia coli heat shock transcription factor $\sigma 32$. EMBO J., 15, 607-617.

9. Hurme,R., Berndt,K.D., Normark,S.J. and Rhen,M. (1997) A proteinaceous gene regulatory thermometer in Salmonella. Cell, 90, $55-64$.

10. Dorman,C.J., Hinton,J.C. and Free,A. (1999) Domain organization and oligomerization among H-NS-like nucleoid-associated proteins in bacteria. Trends Microbiol., 7, 124-128.

11. Hoe,N.P. and Goguen,J.D. (1993) Temperature sensing in Yersinia pestis: translation of the LcrF activator protein is thermally regulated. J. Bacteriol., 175, 7901-7909.

12. Servant,P. and Mazodier,P. (1995) Characterization of Streptomyces albus 18-kilodalton heat shock-responsive protein. J. Bacteriol., 177, 2998-3003.

13. Servant,P., Rapoport,G. and Mazodier,P. (1999) RheA, the repressor of hsp18 in Streptomyces albus G. Microbiology, 145, 2385-2391.

14. Weber,W., Fux,C., Daoud-el Baba,M., Keller,B., Weber,C.C., Kramer,B.P., Heinzen,C., Aubel,D., Bailey,J.E. and Fussenegger,M. (2002) Macrolide-based transgene control in mammalian cells and mice. Nat. Biotechnol., 20, 901-907.

15. Schlatter,S., Rimann,M., Kelm,J. and Fussenegger,M. (2002) SAMY, a novel mammalian reporter gene derived from Bacillus stearothermophilus alpha-amylase. Gene, 282, 19-31.

16. Weber,W. and Fussenegger,M. (2002) Inducible Gene Expression in Mammalian Cells and Mice. In Balbas,P. and Laurence,A. (eds), Recombinant Protein Protocols, 2nd Edn. Humana Press, NJ, in press.

17. Arakawa,H., Hauschild,J. and Buerstedde,J.M. (2002) Requirement of the activation-induced deaminase (AID) gene for immunoglobulin gene conversion. Science, 295, 1301-1306.

18. Djonov,V., Schmid,M., Tschanz,S.A. and Burri,P.H. (2000) Intussusceptive angiogenesis: its role in embryonic vascular network formation. Circ. Res., 86, 286-292.

19. Djonov,V.G., Galli,A.B. and Burri,P.H. (2000) Intussusceptive arborization contributes to vascular tree formation in the chick chorioallantoic membrane. Anat. Embryol., 202, 347-357.

20. Djonov,V.G., Kurz,H. and Burri,P.H. (2002) Optimality in the developing vascular system: branching remodeling by means of intussusception as an efficient adaptation mechanism. Dev. Dyn., 224, 391-402.

21. Weber,W. and Fussenegger,M. (2002) Artificial mammalian gene regulation networks-novel approaches for gene therapy and bioengineering. J. Biotechnol., 98, 161-187.

22. Fussenegger,M. (2001) The impact of mammalian gene regulation concepts on functional genomic research, metabolic engineering and advanced gene therapies. Biotechnol. Prog., 17, 1-51.

23. Cohlan,S.Q. (1977) Tetracycline staining of teeth. Teratology, 15, $127-129$.

24. Iuliucci,J.D., Oliver,S.D., Morley,S., Ward,C., Ward,J., Dalgarno,D., Clackson,T. and Berger,H.J. (2001) Intravenous safety and pharmacokinetics of a novel dimerizer drug, AP1903, in healthy volunteers. J. Clin. Pharmacol., 41, 870-879.

25. Kapunisk-Uner,J.E., Sande,M.A. and Chambers,H.F.S. (1996) Tetracycline, Chloramphenicol, Erythromycin and Miscellaneous Antibacterial Agents, 9th Edn. McGraw-Hill, New York.

26. Triezenberg,S.J., Kingsbury,R.C. and McKnight,S.L. (1988) Functional dissection of VP16, the trans-activator of herpes simplex virus immediate early gene expression. Genes Dev., 2, 718-729.

27. Gossen,M. and Bujard,H. (1992) Tight control of gene expression in mammalian cells by tetracycline-responsive promoters. Proc. Natl Acad. Sci. USA, 89, 5547-5551.

28. Buerstedde,J.M., Arakawa,H., Watahiki,A., Carninci,P.P., Hayashizaki,Y.Y., Korn,B. and Plachy,J. (2002) The DT40 web site: sampling and connecting the genes of a B cell line. Nucleic Acids Res., 30, $230-231$.

29. Weber,W., Kramer,B.P., Fux,C., Keller,B. and Fussenegger,M. (2002) Novel promoter/transactivator configurations for macrolide- and streptogramin-responsive transgene expression in mammalian cells. J. Gene Med., 4, 676-686.
30. Hudson,D.F., Morrison,C., Ruchaud,S. and Earnshaw,W.C. (2002) Reverse genetics of essential genes in tissue-culture cells: 'dead cells talking'. Trends Cell Biol., 12, 281-287.

31. Bezzubova,O., Silbergleit,A., Yamaguchi-Iwai,Y., Takeda,S. and Buerstedde,J.M. (1997) Reduced X-ray resistance and homologous recombination frequencies in a RAD54-/- mutant of the chicken DT40 cell line. Cell, 89, 185-193.

32. Brown,W.R., Mee,P.J. and Hong Shen,M. (2000) Artificial chromosomes: ideal vectors? Trends Biotechnol., 18, 218-223.

33. Cumbers,S.J., Williams,G.T., Davies,S.L., Grenfell,R.L., Takeda,S., Batista,F.D., Sale,J.E. and Neuberger,M.S. (2002) Generation and iterative affinity maturation of antibodies in vitro using hypermutating B-cell lines. Nat. Biotechnol., 20, 1129-1134.

34. Di Noia,J. and Neuberger,M.S. (2002) Altering the pathway of immunoglobulin hypermutation by inhibiting uracil-DNA glycosylase. Nature, 419, 43-48.

35. Sale,J.E., Calandrini,D.M., Takata,M., Takeda,S. and Neuberger,M.S (2001) Ablation of XRCC2/3 transforms immunoglobulin V gene conversion into somatic hypermutation. Nature, 412, 921-926.

36. Harvey,A.J., Speksnijder,G., Baugh,L.R., Morris,J.A. and Ivarie,R. (2002) Expression of exogenous protein in the egg white of transgenic chickens. Nat. Biotechnol., 20, 396-399.

37. Ribatti,D., Vacca,A., Roncali,L. and Dammacco,F. (2000) The chick embryo chorioallantoic membrane as a model for in vivo research on anti-angiogenesis. Curr. Pharm. Biotechnol., 1, 73-82.

38. Yancopoulos,G.D., Davis,S., Gale,N.W., Rudge,J.S., Wiegand,S.J. and Holash,J. (2000) Vascular-specific growth factors and blood vessel formation. Nature, 407, 242-248.

39. Genoux,D., Haditsch,U., Knobloch,M., Michalon,A., Storm,D. and Mansuy,I.M. (2002) Protein phosphatase 1 is a molecular constraint on learning and memory. Nature, 418, 970-975.

40. Malleret,G., Haditsch,U., Genoux,D., Jones,M.W., Bliss,T.V., Vanhoose,A.M., Weitlauf,C., Kandel,E.R., Winder,D.G. and Mansuy,I.M. (2001) Inducible and reversible enhancement of learning, memory and long-term potentiation by genetic inhibition of calcineurin. Cell, 104, 675-686.

41. Pollock,R., Issner,R., Zoller,K., Natesan,S., Rivera,V.M. and Clackson,T. (2000) Delivery of a stringent dimerizer-regulated gene expression system in a single retroviral vector. Proc. Natl Acad. Sci. USA, 97, 13221-13226.

42. Ye,X., Rivera,V.M., Zoltick,P., Cerasoli,F.,Jr, Schnell,M.A., Gao,G., Hughes,J.V., Gilman,M. and Wilson,J.M. (1999) Regulated delivery of therapeutic proteins after in vivo somatic cell gene transfer. Science, 283, $88-91$.

43. Jin,L., Zeng,H., Chien,S., Otto,K.G., Richard,R.E., Emery,D.W. and Blau,C.A. (2000) In vivo selection using a cell-growth switch. Nature Genet., 26, 64-66.

44. Kurosinski,P., Guggisberg,M. and Gotz,J. (2002) Alzheimer's and Parkinson's disease-overlapping or synergistic pathologies? Trends Mol. Med., 8, 3-5.

45. Ngan,E.S., Schillinger,K., DeMayo,F. and Tsai,S.Y. (2002) The mifepristone-inducible gene regulatory system in mouse models of disease and gene therapy. Semin. Cell Dev. Biol., 13, 143-149.

46. Aubel,D., Morris,R., Lennon,B., Rimann,M., Kaufmann,H., Folcher,M., Bailey,J.E., Thompson,C.J. and Fussenegger,M. (2001) Design of a novel mammalian screening system for the detection of bioavailable, noncytotoxic streptogramin antibiotics. J. Antibiot., 54, 44-55.

47. Fussenegger,M., Schlatter,S., Datwyler,D., Mazur,X. and Bailey,J.E. (1998) Controlled proliferation by multigene metabolic engineering enhances the productivity of Chinese hamster ovary cells. Nat. Biotechnol., 16, 468-472.

48. Meents,H., Enenkel,B., Werner,R.G. and Fussenegger,M. (2002) p27Kip1-mediated controlled proliferation technology increases constitutive sICAM production in CHO-DUKX adapted for growth in suspension and serum-free media. Biotechnol. Bioeng., 79, 619-627.

49. Umana,P., Jean-Mairet,J. and Bailey,J.E. (1999) Tetracycline-regulated overexpression of glycosyltransferases in Chinese hamster ovary cells. Biotechnol. Bioeng., 65, 542-549.

50. Favre,D., Blouin,V., Provost,N., Spisek,R., Porrot,F., Bohl,D., Marme,F., Cherel,Y., Salvetti,A., Hurtrel,B. et al. (2002) Lack of an immune response against the tetracycline-dependent transactivator correlates with long-term doxycycline-regulated transgene expression in nonhuman primates after intramuscular injection of recombinant adeno-associated virus. J. Virol., 76, 11605-11611. 
51. Fussenegger,M., Morris,R.P., Fux,C., Rimann,M., von Stockar,B., Thompson,C.J. and Bailey,J.E. (2000) Streptogramin-based gene regulation systems for mammalian cells. Nat. Biotechnol., 18, 1203-1208.

52. Rivera,V.M., Clackson,T., Natesan,S., Pollock,R., Amara,J.F., Keenan,T., Magari,S.R., Phillips,T., Courage,N.L., Cerasoli,F.,Jr et al. (1996) A humanized system for pharmacologic control of gene expression. Nature Med., 2, 1028-1032.

53. Kaufmann,H., Mazur,X., Fussenegger,M. and Bailey,J.E. (1999) Influence of low temperature on productivity, proteome and protein phosphorylation of CHO cells. Biotechnol. Bioeng., 63, 573-582.

54. Boorsma,M., Nieba,L., Koller,D., Bachmann,M.F., Bailey,J.E. and Renner,W.A. (2000) A temperature-regulated replicon-based DNA expression system. Nat. Biotechnol., 18, 429-432.

55. Lundstrom,K. (2001) Alphavirus vectors for gene therapy applications. Curr. Gene Ther., 1, 19-29.

56. Niwa,H., Miyazaki,J. and Smith,A.G. (2000) Quantitative expression of Oct-3/4 defines differentiation, dedifferentiation or self-renewal of ES cells. Nature Genet., 24, 372-376.
57. Blau,H.M. and Banfi,A. (2001) The well-tempered vessel. Nature Med., 7, 532-534.

58. Ferrara,N. and Alitalo,K. (1999) Clinical applications of angiogenic growth factors and their inhibitors. Nature Med., 5, 1359-1364.

59. LeCouter,J., Lin,R. and Ferrara,N. (2002) Endocrine gland-derived VEGF and the emerging hypothesis of organ-specific regulation of angiogenesis. Nature Med., 8, 913-917.

60. Lee,R.J., Springer,M.L., Blanco-Bose,W.E., Shaw,R., Ursell,P.C. and Blau,H.M. (2000) VEGF gene delivery to myocardium: deleterious effects of unregulated expression. Circulation, 102, 898-901.

61. Pollock,R., Giel,M., Linher,K. and Clackson,T. (2002) Regulation of endogenous gene expression with a small-molecule dimerizer. Nat. Biotechnol., 20, 729-733.

62. Rebar,E.J., Huang,Y., Hickey,R., Nath,A.K., Meoli,D., Nath,S., Chen,B., Xu,L., Liang,Y., Jamieson,A.C. et al. (2002) Induction of angiogenesis in a mouse model using engineered transcription factors. Nature Med., 8 , 1427-1432.

63. Zisch,A.H., Schenk,U., Schense,J.C., Sakiyama-Elbert,S.E. and Hubbell,J.A. (2001) Covalently conjugated VEGF-fibrin matrices for endothelialization. J. Control Release, 72, 101-113. 